This item was submitted to Loughborough's Research Repository by the author.

Items in Figshare are protected by copyright, with all rights reserved, unless otherwise indicated.

\title{
Menstrual hygiene in Ugandan schools: an investigation of low-cost sanitary pads
}

PLEASE CITE THE PUBLISHED VERSION

http://dx.doi.org/10.2166/washdev.2012.067

PUBLISHER

(C) IWA Publishing

VERSION

AM (Accepted Manuscript)

LICENCE

CC BY-NC-ND 4.0

REPOSITORY RECORD

Crofts, Tracey, and Julie Fisher. 2019. "Menstrual Hygiene in Ugandan Schools: An Investigation of Low-cost Sanitary Pads". figshare. https://hdl.handle.net/2134/9399. 
This item was submitted to Loughborough's Institutional Repository (https://dspace.lboro.ac.uk/) by the author and is made available under the following Creative Commons Licence conditions.

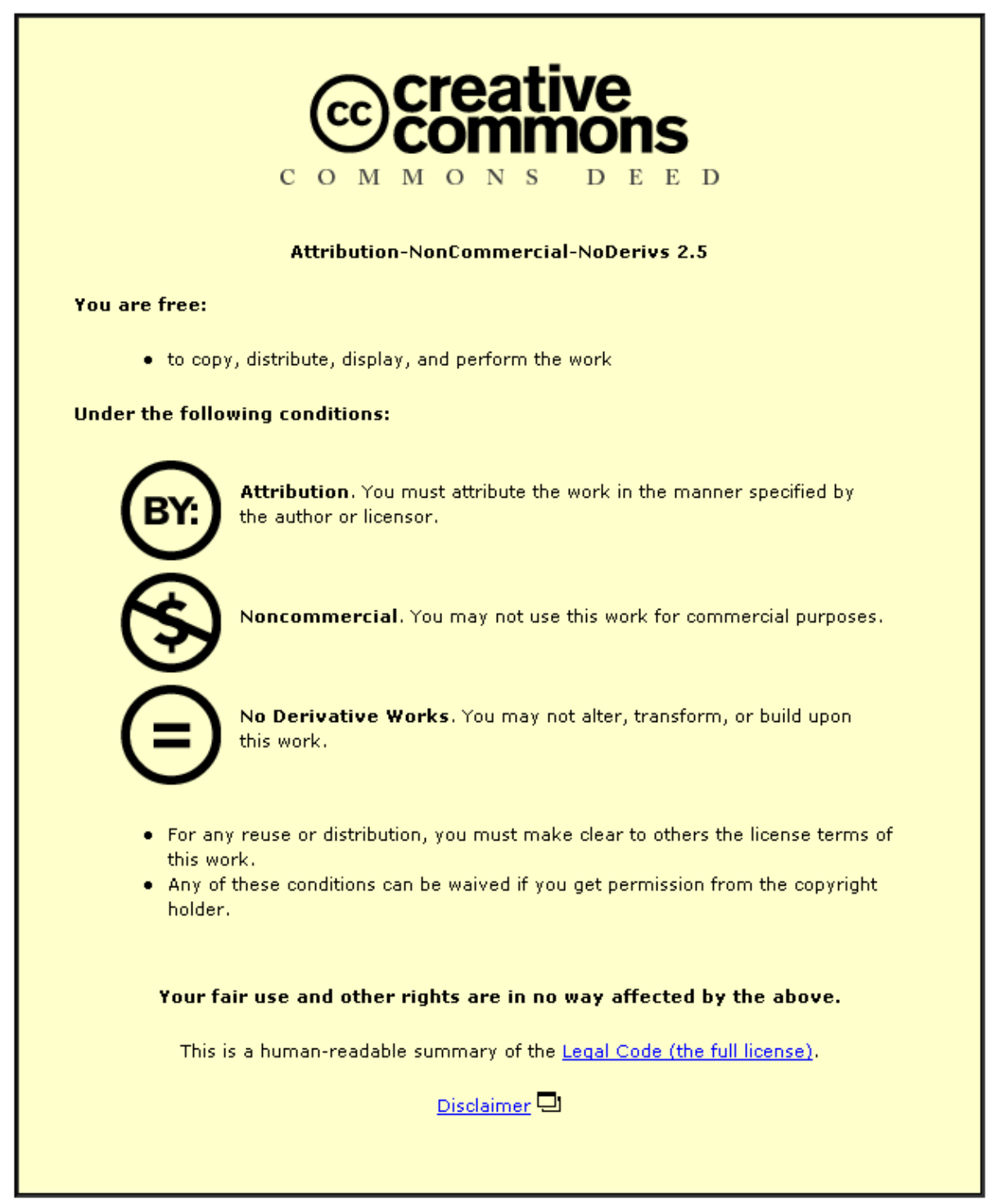

For the full text of this licence, please go to: http://creativecommons.org/licenses/by-nc-nd/2.5/ 
Menstrual Hygiene in Ugandan schools: An Investigation of Low-cost Sanitary Pads

Tracey Crofts, Freelance Consultant, Phone +44 (0) 7816322041 Email tjcrofts@gmail.com Julie Fisher, Research Associate, Water, Engineering and Development Centre (WEDC), Loughborough University, Phone +44 (0) 1509 222393, Fax +44 (0) 1509 211079, Email j.fisher1@lboro.ac.uk 


\begin{abstract}
Menstrual hygiene management (MHM) is a largely overlooked issue in the water, sanitation and hygiene (WASH) sector. Every day, millions of menstruating girls and women in low-income countries struggle to find clean water for washing, private places for changing and adequate blood absorbing materials. This study aims to explore the difficulties experienced by schoolgirls in Uganda in managing menstrual hygiene and investigates the extent to which low-cost sanitary pads are part of the solution. Low-cost sanitary pads, either re-usable or disposable, are a timely, simple and innovative means of improving menstrual hygiene and of addressing a broader set of problems related to MHM in schools. Other factors highlighted are: pain relief, education, safe water provision, clean and private latrines, hygienic and secure bathing facilities, use of soap, sealed waste disposal points, private drying places, anal cleansing materials and effective facility operation and management strategies.
\end{abstract}

Keywords: girls, hygiene, menstruation, pads, sanitation, schools 


\section{Introduction}

Menstrual hygiene is a largely overlooked issue in the WASH sector. Every day, an estimated 200 million menstruating girls and women in low-income countries struggle to find clean water for washing, private places for changing and adequate blood absorbing materials. Social systems, political indifference and cultural customs can compound these problems. However, in the last five years, the emergence of Menstrual Hygiene Management (MHM) is enabling public health issues specific to women to reach national and international agendas. In part, this is due to governments, institutions and NGOs realising that without addressing obstacles related to menstrual hygiene, the achievement of many of the Millennium Development Goal targets (United Nations, 2011) will be hampered (Tjon Ten, 2007). Examples are: the elimination of gender disparity in education (target 3A); increasing sustainable access to basic sanitation (target 7C); and the full and productive employment for all, including women (target 1B).

Schools have become the focus of recent research into MHM in Africa (Sommer, 2010). While there is evidence to suggest a correlation between the onset of menses and school dropout rates (Stewart and Mutunga, 2007), the supposition that menstruation is a direct cause of this is contested (Grant et al, 2010). Among those who are convinced about the reality of menstrual related absenteeism, the extent to which a lack of sanitary protection materials contributes to this is disputed. Scott et al (2009) provided sanitary pads to young women in Ghana, and claimed that this significantly decreased absenteeism. Oster and Thornton (2010), who conducted a randomised trial of menstrual cups in Nepal, noted that menstrual products made little difference to the number of schooldays missed. Given how complicated menstrual related absenteeism is to measure (based on a sensitive topic and often poor attendance data), girls' participation and self esteem may be a more useful way to ascertain the impact of menses on schooling. There is a need for development practitioners to look beyond sanitary protection hand outs to more fully understand the relationship 
between education, poverty and MHM.

\section{Low-cost pads}

Across sub-Saharan Africa schoolgirls tend to use two main types of sanitary protection materials. Those can afford to, opt for imported commercially produced sanitary pads. Most girls who are poor typically use pieces of material, folded and placed into underwear (Verdemato, 2005). These 'cloths' are usually washed and re-used. Other blood absorbing materials include toilet paper, leaves, newspaper, cotton wool and extra layers of clothing.

Commercially produced disposable sanitary pads are too expensive for most African schoolgirls (Kinoti, 2008). In Uganda, a packet of 10 pads costs on average US\$1.35, which is more than the daily income of many working parents. In comparison, cloths, which may be taken from rubbish heaps, are considered to be less hygienic because they may not get washed thoroughly (Verdemato, 2005). Chafing can occur if cloths are not dried thoroughly or have poor absorbency (Seymour, 2009). Low-cost sanitary pads are designed to bridge the gap between these two materials.

This research is focused around two small scale low-cost sanitary pad businesses in Uganda, namely Afripads and Makapads. Afripads were developed in 2009 and are made from sewn materials that are designed to be washed and re-used (see Figure 1). They are sold directly to schoolgirls and NGOs. Made from polycotton blend fabric and impermeable material, their manufacture does not rely on electricity, which enables workshops to be located in rural settings. An Afripads menstrual kit is designed to last for a year.

Makapads were designed in 2003 and are disposable, one use pads (see Figure 2). Supported by UNHCR, they were initially targeted towards refugees, although supply to NGOs has grown steadily. Most Makapads are given to schoolgirls free of charge. They are made from layers of 
waste paper pulp and softened papyrus reed stem fibres, sealed between non woven imported sheets: a permeable layer on top and an impermeable layer underneath.

Figure 1: Example of a lowcost, washable sanitary pad, produced by Afripads

Figure 2: Example of a low-cost, disposable sanitary pad, produced by Makapads
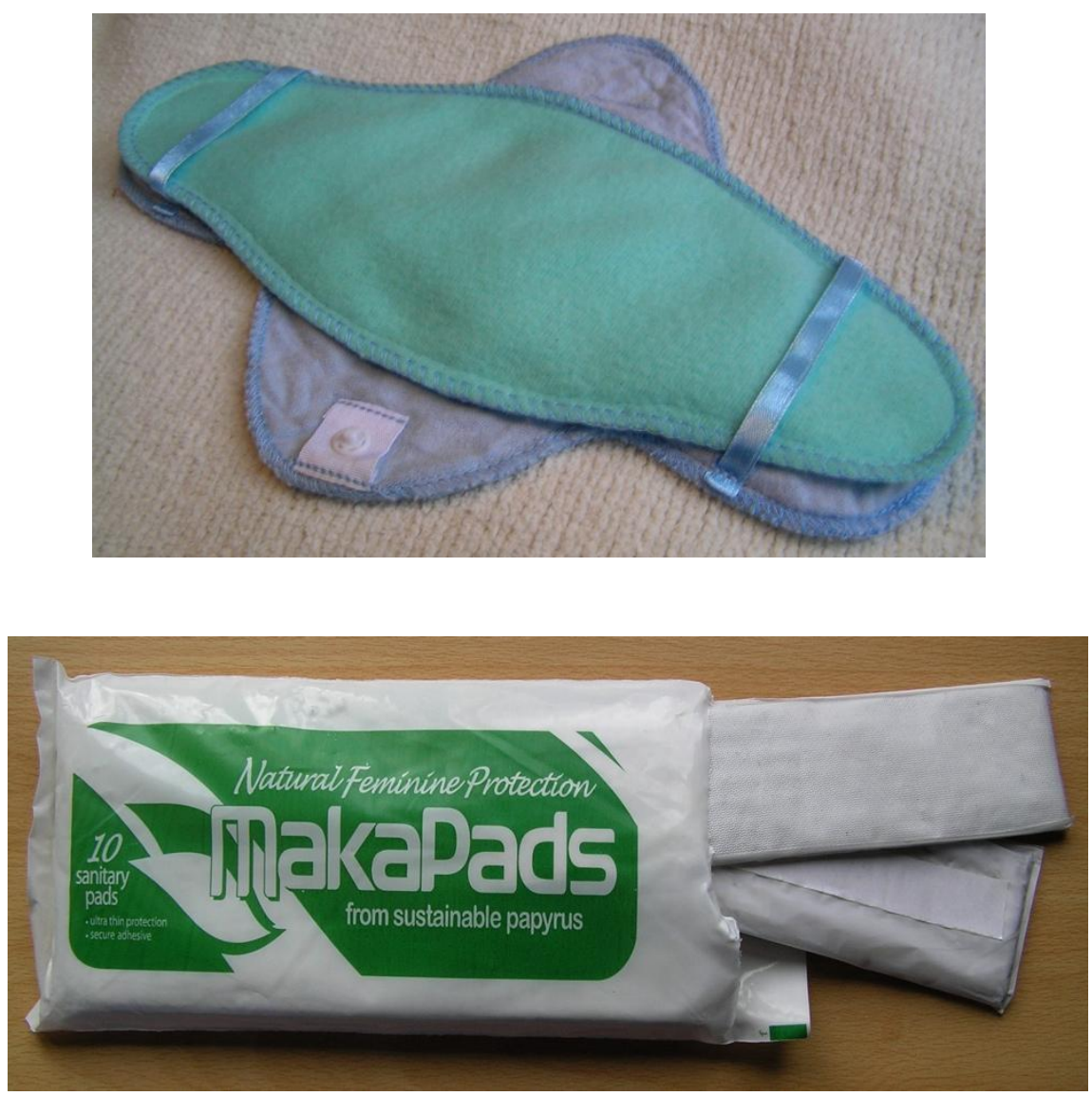

This paper explores the difficulties experienced by schoolgirls in Uganda in managing menstrual hygiene and investigates the extent to which low-cost sanitary pads are part of the solution. The research had the following objectives:

- Summarizing the main problems identified by schoolgirls in managing their own periods;

- Investigating the solutions to such problems;

- Determining whether the provision and use of low-cost pads significantly alleviates the problems;

- Evaluating the potential of low-cost pad designs, production and distribution. 
The findings are taken from a Masters research project carried out at WEDC (Water, Engineering and Development Centre, Loughborough University) (Crofts 2010).

\section{Methods}

\section{Overall approach}

A Participatory Learning and Action (PLA) approach was used to empower schoolgirls through participating in discussions about their MHM issues (Myers, 1999). The study was designed to foster inductive reasoning whereby ideas emerging during the research process could be explored further (Kitchen and Tata, 2000). Hence, there were no preconceived theories to test. The researcher's role was to facilitate learning among participants about their needs and opportunities in order to comprehend their daily experiences. This approach, rooted in phenomenological and feminist thinking, encouraged all voices to be heard and prevented assumptions about menstrual hygiene problems and practices.

\section{Data collection}

A holistic view of menstrual hygiene management was developed using four methods: participatory activities, key informant interviews, site visits and observations of facilities. The participatory activities were the principal source of information, as these focused on schoolgirls, the main research subjects. Owing to the sensitive nature of the topic, caution was applied regarding quantitative data collection because self reporting about hygiene behaviour can be unreliable (Judah et al, 2009). Consequently, qualitative data captured general principles and attitudes; the exception being during observations of facilities where a quantitative ranking tool was devised and used. 


\section{Participatory activities}

Participatory activities were undertaken to fully understand the schoolgirls' opinions and evaluate whether low-cost pads were a solution to their monthly needs. 134 schoolgirls, mostly from the Buganda tribe in southern Uganda, completed the activities outlined in Table 1. Forty focus groups were conducted in 18 secondary schools. Schools were selected based upon distribution of pads: in 10 schools, girls had access to Afripads, in four schools, girls had access to Makapads, and in four randomly selected schools in the same districts as the aforementioned schools, girls had no access to low-cost pads. Groups of two to four girls in the same academic year (Senior 2, 3, or 4) were selected by the head teacher to take part in the 60-90 minute focus group activities in a private place (e.g. under a tree on the edge of the school compound or in an empty classroom). All participants were assured of anonymity. The girls were aged between 13 to 20 (average age of 16) and all had begun menstruating. Female translators were employed for 15 groups where the girls' level of English was poor.

Table 1: Participatory activity descriptions

\begin{tabular}{|c|c|c|}
\hline Activity & Description & $\begin{array}{l}\text { Data Collection } \\
\text { Method }\end{array}$ \\
\hline $\begin{array}{l}\text { Prioritizing } \\
\text { problems }\end{array}$ & $\begin{array}{l}\text { Girls wrote menstrual related problems on pieces of card } \\
\text { and placed them in a ladder formation to rank the biggest } \\
\text { challenges faced in school }\end{array}$ & $\begin{array}{l}\text { Photographs of cards in } \\
\text { priority order and note } \\
\text { taking about key } \\
\text { discussion points }\end{array}$ \\
\hline $\begin{array}{l}\text { Identifying } \\
\text { solutions }\end{array}$ & $\begin{array}{l}\text { Highest ranked problems were used as a discussion starter } \\
\text { about ways to improve menstrual hygiene in order to } \\
\text { determine the girls' coping strategies and abilities to solve } \\
\text { their own problems. }\end{array}$ & $\begin{array}{l}\text { Recording discussions } \\
\text { on a dictaphone }\end{array}$ \\
\hline Questionnaires & $\begin{array}{l}\text { Semi structured questionnaires generated conversations } \\
\text { about hygiene behaviour including the use of sanitary } \\
\text { products }\end{array}$ & $\begin{array}{l}\text { Girls completed } \\
\text { questionnaire answer } \\
\text { sheets }\end{array}$ \\
\hline
\end{tabular}




\begin{tabular}{|l|l|l|}
\hline Scenario & $\begin{array}{l}\text { Imagining they were president of Uganda, participants } \\
\text { devised a series of recommendations about ways the } \\
\text { government could help girls better manage their monthly } \\
\text { periods. This activity enabled the participants' opinions of } \\
\text { macro scale needs and solutions to governance challenges } \\
\text { to be heard. }\end{array}$ & $\begin{array}{l}\text { Recording discussions } \\
\text { on a dictaphone and }\end{array}$ \\
& note taking about key \\
& \\
\hline
\end{tabular}

\section{Key informant interviews}

Nine sanitary pad business leaders were interviewed about their business set up and marketing strategies. Twelve school staff (including three males) with responsibility for schoolgirls' welfare were interviewed about their perspectives on girls' menstrual hygiene behaviour: four head teachers, four teachers, two senior women, the matron of a boarding house and a school counselor. All interviews were recorded using a dictaphone.

\section{Site visits}

Low-cost pad manufacturing sites were visted and information about production was recorded through photographs and note taking. Two Afripads workshops were visited both with 25 employees; in Kitengasi, Masaka District and in Villa Maria, Rakai District. These were open plan production centres where all stages of manufacturing took place. In contrast, the multi stage manufacturing of Makapads happened in specific places relevant to the production processes: collection of papyrus and waste paper, preparation of papyrus fibres (typically by a village women's group), assembly of absorbent materials (typically in an outdoor area exposed to sunlight), packaging and sterilization of products. Two distinct production groups were visited: around the capital city of Kampala and in Kyaka II Refugee Settlement, a community of mostly Congolese and Rwandan refugees in Kyenjojo District. Data were recorded through photographs and note taking.

\section{Observations}


Facilities were surveyed in the 18 secondary schools where focus group activities were conducted. Based on a five criteria scoring tool (looking at water access, sanitation, site cleanliness, hand washing stations and the classroom environment) the facilities were rated from 1 to 10 , out of an overall score of 50. The schools were ranked, with the highest scoring third as 'good', the mid scoring third as 'medium' and the lowest scoring third as 'poor'. This assumes a loose correlation between the quality of facilities and economic standing and therefore academic achievement.

\section{Data analysis}

Data obtained through participatory activities were classified according to the behavioural themes that emerged (e.g. bathing or washing of sanitary pads). These themes were then compared to note connections and discrepancies in MHM (e.g. perceptions of teachers, low-cost pad producers, and the girls). Graphical representations were made from the answers to closed questions in the questionnaires so that patterns could be observed visually. The use of a scoring and ranking tool generated quantitative data from the problem prioritisation activity and school quality observations. These data sets were compared against qualitative patterns to identify associations. Quotes capturing the recurring opinions of participants were written down verbatim.

\section{Results and discussion}

Much was learned about the girls' day to day management of menstruation, in particular, about hygiene protection materials, cleanliness, changing pads and the disposal of used materials.

\section{Girls' use of female hygiene protection materials}

\section{Commercially produced disposable sanitary pads}

Schoolgirls indicated that they preferred commercially produced, disposable sanitary pads (CDSPs), such as Always and Stayfree, if price were not a consideration. They do not require washing, they rarely leak, and are lightweight and secure in underwear. CDSPs were seen as a high quality 
product used by the wealthy or a luxury product for the poor. Girls from good schools considered CDSPs to be the "modern" way to deal with menstruation. Consequently, CDSPs were used most in good schools, low-cost products were used most in poor schools, and traditional materials were used by a few girls from all schools.

On average, a year's supply of CDSPs cost ten times more than an annual supply of Afripads and three times more than Makapads. Girls who were able to afford CDSPs tended not to use low-cost products. In the same way that investment in sanitation enables people to progress to the next 'rung' of the sanitation ladder (Morella et al, 2008), so wealthier schoolgirls mentioned that they were unlikely to ever use low-cost products or traditional materials.

\section{Afripads}

The main reasons schoolgirls used Afripads (Figure 1) were that they were "soft" to wear, "reliable" (as in leakproof) and "cheap" (in comparison to CDSPs). When asked to compare them to CDSPs, 28 out of 29 Afripads users, considered them to be better, although the extent to which this was based upon value for money or product design was unclear. The popularity of Afripads was demonstrated during the 'imagine you are president' exercise, in schemes to distribute Afripads (e.g. "More clinics should sell Afripads", "Afripads should extend their services far away"). Schoolgirls who had access to Afripads but chose not to purchase them typically gave one of two reasons: firstly, affluent girls attending good schools considered washing materials to be "dirty" and "irritating". Secondly, girls from poor schools, perceived Afripads to be expensive in comparison to traditional materials. The expense was often associated with the initial cost of an Afripads menstrual kit.

\section{Makapads}

The absorbency and thinness of Makapads (Figure 2) was the main concern for girls. A number of girls had tried Makapads, but had reverted back to cloths. The leakage may have been more to do 
with the shape of the pad as they were rectangular, lacking 'wings' (protrusions either side to be folded underneath underwear). In loose fitting underwear, Makapads were unreliable in preventing blood stains. That Makapads were supplied for free was the main reason for their use, and only $30 \%$ of girls said they would purchase them.

\section{Traditional materials}

Cloths, leaves, newspaper, cotton wool and toilet paper are readily available in most Ugandan towns and villages. Cloths and old paper were used because they were free, usually recycled from home. Toilet paper and cotton wool were available in small stores and kiosks. Menstrual cloths were made by folding a strip of material, preferably cotton, and placing it on the crotch of the underwear. Many girls feared that if they moved too much the cloth would fall out, discouraging them from sports or walking long distances. To compensate, girls would wear their tightest underwear during menstruation.

Cotton wool was only used by a few girls. A wad of it is wrapped in gauze or a strip of cotton fabric. The cotton wool is disposed of but the cloth is washed for re-use. The amount of cotton wool was calculated by trial and error, with the potential for miscalculating flow rates often causing apprehension.

Toilet paper was used in a similar manner to cloths as a wad was placed inside a girl's underwear. Typically a girl required two rolls of toilet paper per menstrual cycle, and had to change this more regularly than CDSPs. Girls reported walking differently when wearing such materials to limit the chances of them falling down, making them self conscious and anxious.

\section{Insertion products}

Blood absorption by tampons, menstrual cups, sponges or leaves was rare. Only one girl knew about (and used) tampons although most girls were intrigued by them. A lack of knowledge of and 
accessibility to tampons were the main reasons given for not using them. In reality, low demand meant high prices, which was also assumed to be a significant limiting factor; a few teachers associated tampons with the "rich classes". Despite being curious, most girls stated that they would not use insertion products even if they became more widely available for fear they would "get stuck", be difficult to insert or painful. Insertion materials generally were seen as culturally inappropriate, with girls questioning their effects on fertility and health.

\section{Choice of pads}

Most girls reported using a combination of reusable/disposable, cheap/expensive menstrual protection materials. This largely depended on flow rates, activity levels, the need for discretion, available money and time of day. For example, a boarding school student with a heavy flow going on a long walk at the beginning of term (when she still had pocket money) would be more likely to use CDSPs than a day scholar at the end of her monthly period at home in the evening.

\section{Girls’ Menstrual Hygiene Practices}

\section{Water supply and personal cleanliness}

In most of the schools visited, water and sanitation facilities were inadequate for menstruating girls to clean themselves during the day. Latrine blocks and bathing shelters had no toilet paper for anal cleansing, so girls relied on old pieces of paper, or hands and water. Half the schools visited had onsite water such as an outside standpipe or hand pump, but only one sanitation block had water with an inconsistent supply. In all other cases, water was collected by bucket, basin or jerrycan and taken into the latrine block or bathing shelter. It was acceptable for boarders to be seen carrying water into sanitation facilities before or after school, but girls were reluctant to carry water during the day as it would indicate they were menstruating. Consequently poor hygiene and embarrassment were widespread. 


\section{Sanitation facilities}

The design and layout of most sanitation facilities suggested that they were not planned with girls' menstrual hygiene needs in mind. Three recurring examples of poor design were:

1) Separate blocks for bathing and excreting proved problematic. Pit latrine disposal points and water were separated. This made girls conscious that other students would become aware of their condition if they were seen moving between locations. There were no bathing shelters in day only schools. In joint day/boarding schools, most day scholars did not use bathing shelters for fear that other students would know they were menstruating.

2) Many school latrines had cubicles with little or no exposure to natural light. This meant that girls could not see stains or check their own cleanliness.

3) Rough latrine and bathing slab surfaces encouraged unsanitary conditions and unpleasant smells. Blood, urine, faeces and grey water were difficult to remove from the pitted flooring.

\section{Facilities for changing pads}

Sanitary protection materials were usually changed at least once a day in school. A few girls avoided changing due to poor hygiene conditions and lack of privacy. Whether at home or at school, $54 \%$ of students usually changed in latrines, $27 \%$ changed in dormitories or bedrooms and $19 \%$ changed in bathing places. Reasons for changing in latrines were that they were the only private place on the school compound and had disposal facilities. Boarding students would sometimes change in the dormitories, behind or between bunk beds (e.g. "I change pads in the dormitory because the latrines are dirty"). Where bed frames did not exist, girls changed discreetly in a corner of the dormitory or under their bed sheets.

$43 \%$ of girls did not feel they had enough privacy to change at school, compared to only $13 \%$ for girls at home. Secure doors and locks were the most significant ways to improve this. Girls were embarrassed to use latrine blocks with the same roof and pit as boys and teachers in case others 
might hear them changing or view their waste through the slab hole. Additionally, some girls were reluctant to go to secluded spaces frequented by older men, fearing sexual assault.

\section{Washing and drying pads}

No day scholar who used washable pads or cloths washed them in school. Instead, they would make one pad last all day, or take the used item home. Most boarders washed their pads in the bathing shelters, whilst washing themselves, although a few washed them in their dormitories. Washing menstrual materials in public spaces was deemed culturally inappropriate. All schoolgirls said they used bar soap or OMO (soap powder) (the ratio being 70:30 respectively). However, these were only observed once in bathing shelters or dormitories, which suggests a variance between girls' knowledge of good hygiene practices and their actual behaviour.

The lack of water also meant that girls could not wash blood stains from skirts. The girls' coping strategies included wrapping a jumper around their waist or absenting themselves from school.

Drying reusable pads and cloths was difficult because they could not be put on public display. $79 \%$ of girls dried menstrual hygiene materials on covered peg hangers in their dormitories or bedrooms. Less than $3 \%$ of girls dried pads and cloths in the sunlight. Away from the sun's bacteria killing properties these could take three days to dry and become malodorous. One in seven girls said they had used materials that were still damp, which they claimed often caused chafing and infection. There is a lack of empirical evidence linking vaginal or urinary infections with this practice, although it is not an unreasonable assumption (Irura, 2008).

\section{Disposal of pads}

Commercial waste management services for used non washable sanitary products were nonexistent. In all but a few latrine blocks no containers were found to dispose of used sanitary pads; none were found in bathing shelters. Consequently, $65 \%$ of girls threw used materials into pit latrines at school 
(e.g. "It's the only convenient place we have"). This resulted in latrines filling up quickly. When pit latrines were lined to enable regular emptying by pumping, the presence of pads and cloths blocked suction hoses, leaving some solid waste in the pit. Despite this, pit latrines were not constructed with capacity for the disposal of menstrual materials.

Although five out of 18 schools had incinerators or burning places, they were little used due to their distance from the latrine blocks or bathing shelters. Schoolgirls would avoid being seen carrying small bundles, especially by men. Even where there were disposal buckets inside the latrine blocks, no management system existed for transferring used pads to the incinerator or burning site. The incinerators did not have sealed chutes into them; many lacked doors or lids, which was unsightly and also attracted vermin. Some girls recounted local myths that a woman would become infertile if a dog were to sniff her sanitary waste, or that a witchdoctor could place a curse on a female if they found their used menstrual materials.

\section{The significance of low-cost pads}

The most cited menstrual related problem was pain, especially abdominal pain (e.g. "If I were president, I would bring them [schoolgirls] some medicine for the pain"). The second most cited problem was a lack of sanitary pads, usually related to price. That pain was the main concern to the girls, was an unexpected, yet significant finding. It does not undermine the need for low-cost pads, but rather substantiates the need for schools and development practitioners to also consider pain relief. Inappropriate facilities and poor physiological understanding of menstruation also compounded girls' difficulties. The fact that girls rarely mentioned these problems implies their acceptance of the status quo and the normalisation of poor service delivery and guidance. Corollary 'solutions' to menstrual related problems were identified as being the availability of pain relief, access to leak proof sanitary protection materials, female friendly sanitation facilities, and education about physiological maturation. These four solutions were not mutually exclusive: advancements in menstrual hygiene can only be made if a holistic approach is taken that addresses all these aspects. 
$33 \%$ of girls cited a lack of pads as the main reason for schoolgirls being absent from school, implying that the provision of low-cost pads could significantly reduce absenteeism amongst girls from mid to lower income families. However, girls who could afford to purchase CDSPs were also interested in purchasing low-cost pads for use as panty liners at the beginning or end of menstruation. Despite a huge variance in perceived and reported levels of menstrual related absenteeism, students from good quality schools thought that girls from poorer backgrounds were more likely to miss school due to their inability to afford CDSPs. However, Grant et al (2010) note that other factors such as the quality of the girls' relationships with their teachers, parental attitudes of the rich and poor towards education, and levels of school engagement in pre-menarche years also affect girls' attendance. Hence, evidence for pad related absenteeism was inconclusive.

\section{Problems of CDSPs}

The numbers of NGOs and donors offering free or subsidized handouts of CDSPs is growing. However, this does not address the underlying poverty related problem. Low-cost sanitary pad businesses are a more sustainable option: in-country production creates employment, which in turn stimulates local economic development.

Low-cost pads are also environmentally friendly (Tjon Ten, 2007). In comparison to CDSPs, they do not contain petroleum based superabsorbent gels and have a smaller ecological footprint. Moreover, Afripads produce less solid waste per year and Makapads claim to use biodegradable natural fibres in their products. As CDSP companies expand their markets into sub-Saharan Africa and campaigns to donate western pads increase, environmental sustainability should be questioned. The implication of more CDSP waste is that pit latrines become used as rubbish pits, thus reducing capacity for excreta and thereby resulting in additional environmental hazards (Bharadwaj and Patkar, 2004). 


\section{Potential of low-cost pads}

Afripads and Makapads are examples of small scale, localised sanitary pad manufacturers. Although other similar start-ups are emerging, such as SHE in Rwanda ${ }^{1}$, no low-cost pad manufacturing is taking place at scale in sub-Saharan Africa. The market potential for low-cost pads is huge, and competition is likely if donations of CDSPs do not undermine local manufacturers. Lessons are available from some Asian countries that are further ahead in low-cost pad production (e.g. BRAC's Sanitary Napkin Production Centre in Maneckgani, Bangladesh²). In order to manufacture pads at scale more research is needed into distribution possibilities.

Both Afripads and Makapads make assumptions upon which the success of their products is based. Afripads assumes customers have access to clean water and soap and effective drying facilities. Makapads relies upon electricity for sealing and sterilization and assumes that the pads are biodegradable despite not having conducted robust tests to this end.

One of the biggest challenges to low-cost pad manufacturers is balancing quality with cost. This means keeping the per unit cost competitive with that of the cheapest CDSPs. For Afripads, it also means convincing customers of the cost benefits associated with annual, as opposed to monthly, pad acquisition. Ironically, buying toilet paper as an alternative is significantly more expensive than an Afripads kit over the course of a year.

\section{Conclusions}

The market for low-cost sanitary pads lies between free unhygienic rags and the expensive commercial hygiene products. The production and distribution of low-cost sanitary pads, either re-

\footnotetext{
${ }^{1}$ http://sheinnovates.com/index.html

2 http://www.brac.net/content/social-enterprises-health
} 
usable or disposable, is a timely, simple and innovative means of improving MHM, and is one that needs to be implemented as part of a holistic approach to improve the experience of millions of girls in low-income countries.

Unless the cost of CDSPs is reduced and they can be disposed of hygienically with minimal environmental detriment, there is a strong market for low-cost sanitary pads. How they are developed and the popularity of reusable versus disposable pads remains to be seen. However, part of the broader holistic approach is an understanding that the lack of pain relief and education are problems on a par with a lack of pads. Additional considerations need to be the provision of adequate and safe water, clean and private latrines, hygienic and secure bathing facilities, soap, sealed waste disposal points, private drying places, anal cleansing materials and effective facility operation and management strategies. Future research necessitates the WASH sector listening to the voices of menstruating poor women and schoolgirls to more fully understand their hygiene practices, preferences and needs.

\section{References}

Bharadwaj, S. \& Patkar, A. 2004 Menstrual hygiene and management in developing countries:

Taking stock. Social Junction: India. Available at www.mum.org/menhydev.htm (Accessed 6/4/11).

Crofts, T. 2010 Will They Cotton On? An Investigation into Schoolgirls Use of Low-Cost Sanitary Pads in Uganda. MSc Dissertation, WEDC, Loughborough University.

Grant, M., Lloyd, C. and Mensch, B. 2010 Gender, Absenteeism and Menstruation: Evidence from Rural Malawi. Population Association of America 2010 Annual Meeting Program.

Irura, C. 2008 Women, water and sanitation: going the extra mile. Pambazuka News 379, 10 June 2008. Available: http://www.pambazuka.org/en/category/comment/48637\# (Accessed 18/03/09). Judah, G., Aunger, R., Schmidt, W., Michie, S., Granger, S. and Curtis, V. 2009 Experimental 
Pretesting of Hand-Washing Interventions in a Natural Setting. American Journal of Public Health 99, (S2) S405-S411.

Kinoti, K. 2008 Interview with Shiphrah Gichaga of the Forum for African Women Educationalists Kenya Chapter (FAWEK). Resource Net Friday File Issue 231, June 2005. Available at http://www.awid.org/Library/Menstruation-and-gender-disparities-in-education (Accessed 17/3/10). Kitchen, R. and Tate, N. 2000 Conducting research into human geography: Theory, methodology and practice. Prentice Hall, Essex.

Oster, E. and Thornton, R. 2011 Menstruation, Sanitary Products and School Attendance: Evidence from a Randomized Evaluation. American Economic Journal: Applied Economics 3, (1) 91-100.

Morella, E., Foster, V. and Banerjee, S. 2008 Climbing the Ladder: The State of Sanitation in SubSaharan Africa. Africa Infrastructure Country Diagnostic. The World Bank,Washington DC.

Myers, B. 1999 Walking with the poor: Principles and practices of transformational development. Orbis, New York.

Scott, L., Dopson, S., Montgomery, P., Dolan, C. and Ryus, C. 2009 Impact of Providing Sanitary Pads to Poor Girls in Africa. Oxford University, Oxford.

Seymour, K. 2009 Bangladesh: Tackling Menstrual Hygiene Taboos. Sanitation and Hygiene Case Study 10. UNICEF, New York.

Sommer, M (2010) Putting menstrual Hygiene Management on to the School Water and Sanitation Agenda. Waterlines 29, (4) 268-278.

Stewart J. and Mutunga, P. 2007 Life Skills, Sexual Maturation and Sanitation: What's (Not) Happening in our Schools - An Exploratory Study from Kenya, Uganda and Zimbabwe. African Studies Review 50 199-201.

Tjon Ten, V. 2007 Menstrual Hygiene: A Neglected Condition for the Achievement of Several Millennium Development Goals. Europe External Policy Advisors, Netherlands.

United Nations 2011 Millennium Development Goals. Available at www.un.org/millenniumgoals (Accessed 6/4/11). 
Verdemato, T. 2005 Responding to Women's Menstrual Hygiene Needs in Emergencies: A Case Study from Katakwi, Uganda. MSc Thesis: Cranfield University, UK. 